\title{
Antidepressants in the treatment of fibromyalgia
}

\author{
Chantal Moret \\ Mike Briley \\ NeuroBiz Consulting \& \\ Communications, Les Grèzes, La \\ Verdarié, 81100 Castres, France
}

Correspondence: Chantal Moret

NeuroBiz Consulting \&

Communications, Les Grèzes, La Verdarié,

8II00 Castres, France

Tel/Fax +33563590735

Email chantal.moret@neurobiz.com

\begin{abstract}
Fibromyalgia syndrome is a chronic disease of widespread and debilitating pain whose cause is unknown and whose risk factors are poorly understood. It is often comorbid with rheumatoid and other pain disorders as well as psychiatric disorders such as anxiety and depression. Although they are not officially approved for this indication, antiepileptics and antidepressants are often used to treat fibromyalgia. The tricyclic antidepressants (TCAs), particularly amitriptyline, are among the most common treatment strategies. Because of the poor tolerability of the tricyclics, the newer antidepressants have been widely tested in fibromyalgia. The selective serotonin reuptake inhibitors (SSRIs) and the reversible monoamine oxidase inhibitors do not seem to be particularly helpful. The serotonin and norepinephrine reuptake inhibitors (SNRIs), duloxetine and milnacipran, on the other hand, have been shown in placebo-controlled trials to offer significant relief to patients suffering from fibromyalgia. Although no direct comparative studies have been performed, these compounds appear to be as effective as the TCAs but much better tolerated. The effectiveness of the SNRIs as well as other dual acting antidepressants, such as mirtazapine, but not the SSRIs, implies that a dysfunction of both serotonin and norepinephrine neurotransmission probably exists in fibromyalgia. The effectiveness of antidepressants appears to be independent of their effect on comorbid depression.
\end{abstract}

Keywords: fibromyalgia syndrome, FMS, pain, depression, antidepressants, norephinephrine, serotonin

\section{Introduction}

After osteoarthritis, fibromyalgia syndrome (FMS) is the second most common condition seen by rheumatologists with an estimated prevalence in the general population of $2 \%-$ $4 \%$. FMS is a syndrome characterized by a chronic widespread debilitating musculoskeletal pain and stiffness throughout the body (White and Harth 2001; Neumann and Buskila 2003). Etiology and specific risk factors of FMS are poorly understood but most patients $(80 \%)$ are female and frequency tends to increase through middle age and then to decline (White and Harth 2001). The severe disability caused by FMS has been estimated to be comparable to that reported for other rheumatic disorders such as osteoarthritis or rheumatoid arthritis (Hawley and Wolfe 1991), inflammatory myopathies (Sultan et al 2002), and systemic lupus erythematosus (Tench et al 2002). Since generalized pain may be present in other rheumatic entities, diagnosis is not easy. Different rheumatic and non-rheumatic diseases overlap or may be confused with FMS (Martinez-Lavin et al 2001).

Diagnostic criteria for FMS (Wolfe et al 1990) require the presence, for at least 3 months, of widespread chronic pain as judged by pain upon palpation at 11 or more of 18 tender points. In addition to pain, patients with FMS complain of fatigue, sleep disturbances, morning stiffness, depressed mood and cognitive and memory disturbances sometimes referred to as "fibro fog". In addition headaches, irritable bowel syndrome, painful menstrual periods, numbness or tingling of the extremities, restless legs syndrome, temperature sensitivity and a variety of stress-related symptoms and 
neuroendocrinological and immunological dysfunctions are frequently associated with FMS (Henriksson 2003). FMS may be triggered by different stressors (Buskila and Neumann 2002) such as physical trauma, infectious diseases including hepatitis C, Lyme disease, coxsackie B infection, HIV, and parvovirus infection (Barkhuizen 2002), endocrine disorders, immune activation, and emotional distress. Several studies have shown that FMS tends to aggregate in families (Yunus 1998; Arnold et al 2004).

In contrast to what was originally thought, the pathophysiology of FMS appears to reside not in peripheral musculoskeletal alterations (Olsen and Park 1998), but in abnormalities of the central pain processing mechanisms (Bennett 1999, 2005). Cytokines, which are involved in immune responses as well as the regulation of cell growth and repair, also play a role in the expression of pain. In FMS, the cytokines IL-1, IL-6 and IL-8 have been suggested to be dysregulated (Wallace 2006).

Pathways and modulation of pain perception have been described by Kranzler et al (2002) and by Briley and Moret (2003). Nociceptive input is conducted from the periphery to the spinal cord and to brain centers involved in pain perception. Neurokinins, such as substance $P$ and neurokinin $\mathrm{A}$, are released from the peripheral afferent fibers (PAF) and act on neurokinin receptors, such as the NK1 receptor, in the dorsal horn of the spinal cord. The neurokinins are co-released with the excitatory transmitter, glutamate, which acts at postsynaptic NMDA (N-methyl-D-aspartate) and AMPA ( $\alpha$-amino-3-hydroxy-5-methyl-4-isoxazole propionic acid) receptors also localized on neurons in the dorsal spinal cord. The release of these transmitters is modulated by both inhibitory $\alpha_{2}$-adrenergic and $\mu$-opioid receptors and excitatory serotonin $(5-\mathrm{HT})_{3}$ receptors present on PAF. Inhibitory $\alpha_{2}-$ adrenergic, $\mu$-opioid and $5-\mathrm{HT}_{1 \mathrm{~A}}$ are also present postsynaptically on the dorsal horn neuron with inhibitory $\gamma$ aminobutyric acid $(\mathrm{GABA})_{\mathrm{A} / \mathrm{B}}$ receptors. These various receptors are activated by neurotransmitters such as 5-HT, norepinephrine (NE), glutamate, GABA, and enkephalines.

Any of the multiple steps of these pathways can be the site of alterations leading to a state of chronic pain. Brain imaging studies show direct evidence of altered pain processing in FMS (Mountz et al 1995; Bradley et al 2002; Gracely et al 2002). Pain perception from a normally innocuous stimulus (allodynia) and an increased sensitivity to painful stimuli (hyperalgesia) characterize nociceptive processing in patients with FMS (Graven-Nielsen et al 1999; Staud et al 2001). Studies that have shown that patients experience increased sensitivity to mechanical, thermal, and electrical stimulation (Arroyo and Cohen 1993; Granges and Littlejohn 1993; Sorensen et al 1998; Gracely et al 2002; Staud et al 2003) support the hypothesis that FMS is a disorder characterized by an activation of cortical or subcortical pain processing. Modified temporal summation of pain stimuli (wind-up) or sensitization (Geisser et al 2003; Staud et al 2003) occurring at the level of the PAF-dorsal horn neuron synapse, is typical of FMS and reflects an increased response of the dorsal horn neuron to tonic, peripheral nociceptive input. Allodynia and hyperalgesia observed in FMS probably result from similar enhanced responses (Herrero et al 2000).

The hypothalamic-pituitary-adrenal (HPA) axis is one of the major stress response systems in the body. Changes in the HPA axis and stress-response abnormalities have been shown in FMS (Crofford 1998; Neeck and Crofford 2000) and other chronic pain disorders (McBeth et al 2005). FMS often develops in conjunction with, or is worsened by, hormonal imbalances indicating a disruption in the body's stressresponse systems. Crofford et al (1996) have proposed that FMS should be considered as a "stress-associated syndrome". Levels of the stress hormone, cortisol, have been reported to be modified in patients with FMS. Higher baseline levels of cortisol have been reported in patients with FMS compared with controls (Catley et al 2000). Lowered cortisol levels have, however, also been observed in patients with FMS (Gur et al 2004; Fries et al 2005), one study showing a significant correlation between cortisol levels and number of tender points in FMS patients (Gur et al 2004). These conflicting results have led to suggestions that the HPA axis may be either hyperactive or hypoactive (Kranzler et al 2002). Fatigue, sleep disturbance, the presence of depressive symptoms, and the age of the patient all influence cortisol levels so that it is difficult to interpret these data in terms of cause or effect.

Sleep disturbances occur frequently in patients with FMS. An increase in sleep latency, low sleep efficiency, a decrease in slow-wave sleep, an increase in alpha sleep (stage 1), and an increase in awakenings have all been reported (Roizenblatt et al 2001). The occurrence of daytime hypersomnolence in patients is linked to a greater severity of FMS symptoms and to more severe polysomnographic alterations (Sarzi-Puttini et al 2002).

Fatigue is also an important symptom of FMS that can be mild in some patients and yet incapacitating in others. The fatigue has been described as "brain fatigue", in which patients feel totally drained of energy. It has also been referred as "brain fog". Many patients describe this situation by 
saying that they feel as though their arms and legs are tied to concrete blocks, and they have difficulty concentrating. With the introduction of different instruments (Mease 2005) it is now possible to quantify various types of physical and emotional fatigue.

FMS and major depression commonly co-occur; $20 \%-40 \%$ of patients diagnosed with FMS also suffer from depression, with a lifetime prevalence of up to $70 \%$ (Epstein et al 1999; Hudson et al 1985, 1992). A more recent study (Kassam and Patten 2006) conducted in a large sample from the general population has shown that the annual prevalence of major depression was three times higher in subjects with FMS $(22.2 \%)$ than in those without FMS (7.2\%). There is strong evidence for an association between FMS and major depressive disorder, including overlapping symptomatology, similar pattern of comorbid disorders, high rates of major depressive disorder among relatives of patients with FMS, similar pattern of responses to psychological tests and rating scales, and the high lifetime rates of mood disorders in FMS (Hudson and Pope 1996). FMS co-aggregates with major mood disorder in families (Arnold et al 2004), suggesting that mood disorders and FMS may share some of the inherited genetic factors possibly involved in the etiology of both disorders. Similar biological changes have been found in both disorders, including disturbed HPA-axis, modified responses to NE (Adler et al 1999) and decreased cerebral spinal fluid levels of NE (Russell et al 1992a). Sleep abnormalities in FMS are similar to those associated with 5-HT dysfunction (Moldofsky et al 1975) frequently found in depressed patients. Low serum 5HT concentrations and altered density of 5-HT transporter binding sites (determined with $\left[{ }^{3} \mathrm{H}\right]$ imipramine or $\left[{ }^{3} \mathrm{H}\right]$ paroxetine) in postmortem brain tissue and in platelets of drug-free FMS patients (Legangneux et al 2001; Russell et al 1992b; Owens and Nemeroff 1994) as well as the possible association of the disease with the short form of 5-HT transporter (considered to be a risk factor for depression) (Offenbaecher et al 1999; Cohen et al 2002) further reinforce the hypothesis of an association between FMS and depression.

Fibromyalgia can be classified as a "functional somatic syndrome". This classification includes a number of overlapping syndromes such as irritable bowel syndrome (IBS), chronic fatigue syndrome, and more than 10 other syndromes which all strongly overlap with depression and anxiety (Weir et al 2006). Recent evidence suggests that genetic and familial factors participate in the pathogenesis of these syndromes and that fibromyalgia and other functional somatic syndromes may share a number of heritable pathophysiologic features (Buskila et al 2005). The hyperalgesia experienced in IBS is thought to result, at least partially, from sensitization of spinal cord dorsal horn neurons (Price et al 2006) and in this respect its pharmacopathology probably has certain features in common with fibromyalgia. In fact, patients with fibromyalgia are 3-4 times more likely to suffer from co-morbid IBS than the general population (Kurland et al 2006; Vandvik et al 2006; Weir et al 2006).

\section{Treatment of fibromyalgia}

The multifaceted nature of the disease makes FMS difficult to treat. Determination of efficacy and the definition of response are also difficult. Improvement of pain is the most common outcome measure, usually evaluated with visual analog scales. Fatigue, sleep, and global well-being are also evaluated with self-administered instruments. The self-reported, Fibromyalgia Impact Questionnaire (FIQ) subscales assess various symptoms and collectively give an estimation of overall function (Burckhardt et al 1991; Dunkl et al 2000), although most researchers accept that the instrument has significant limitations (Bennett et al 2005). The different subscales of the FIQ determine physical functioning, work status, depression, anxiety, morning tiredness, pain, stiffness, fatigue, and wellbeing during the preceding week. Psychological function is evaluated with FIQ subscales for depression and anxiety. Standard depression scales such as Hamilton Depression Rating Scale, Montgomery Asberg Depression Rating Scale or the Beck Depression Inventory are also frequently used.

FMS is generally refractory to many of the therapies that have been tried (Crofford and Clauw 2002; Rao and Clauw 2004). A certain number of non-pharmacologic treatments including psychotherapy appear, however, to offer some relief in some patients (Leventhal 1999; Goldenberg et al 2004; Sarac and Gur 2006). Although no drugs are currently approved for FMS by health authorities of any country, a broad array of medications is routinely used. For many, there is no scientific evidence of efficacy, while evidence for efficacy of many others is weak (Leventhal 1999; Goldenberg et al 2004). Modest, although statistically significant, efficacy has been demonstrated for the opiate analgesic, tramadol, alone (Biasi et al 1998) or combined with the analgesic antipyretic, acetaminophen (Bennett et al 2005). The most convincing demonstration of activity of a non-antidepressant drug has been with pregabalin, an antiepileptic drug, alpha(2)-delta ligand acting on GABA receptors, which is already approved in many countries for the treatment of neuropathic pain. A multicenter, double-blind, 8-week, randomised clinical trial comparing 
pregabalin (450 mg/day) with placebo in 529 patients with FMS showed that pregabalin was effective in reducing symptoms of pain, disturbed sleep, and fatigue compared with placebo. Reduction of pain intensity by at least $50 \%$ was achieved in $29 \%$ of patients with pregabalin compared with only $13 \%$ on placebo. Improvements in global measures and health-related quality of life were also greater with pregabalin (Crofford et al 2005).

\section{Antidepressant treatment of fibromyalgia}

The frequent comorbidity of FMS with depression has naturally favored the use of antidepressant medication in FMS. Antidepressants are now the most widely studied and, for certain, the most successful therapy of fibromyalgia (Goldenberg et al 2004; Bennett 2005).

\section{Monoamine oxidase inhibitors}

There is no evidence that monoamine oxidase inhibitors (MAOI) are effective in the treatment of FMS. The only study to investigate the activity of irreversible MAOIs in FMS found them to offer no benefit with the possible exception of combination of MAOI and 5-HTP (Nicolodi and Sicuteri 1996). The stress- and/or diet-related adverse events seen in this study indicate that these drugs are not suitable for FMS patients. A study (see below for details) comparing the reversible MAOI, moclobemide, and the tricyclic antidepressant (TCA), amitriptyline, and placebo in the treatment of FMS in women without psychiatric disorder, concluded that moclobemide was not helpful (Hannonen et al 1998).

\section{Tricyclic antidepressants}

In 1986, two randomized placebo-controlled trials demonstrated the effectiveness of amitriptyline in FMS. The administration of amitriptyline ( $50 \mathrm{mg} / \mathrm{d}$ at bedtime) to 27 patients with FMS for 9 weeks resulted in significant improvements in pain, stiffness and sleep compared to 32 patients treated with placebo (Carette et al 1986). In the second study (Goldenberg et al 1986) 62 patients with FMS received either amitriptyline $(25 \mathrm{mg} / \mathrm{d}$ at bedtime $)$, the non-steroidal anti-inflammatory drug, naproxen (500 mg twice daily), both amitriptyline and naproxen, or placebo for 6 weeks. Patients administered amitriptyline had significant improvement in pain, sleep difficulties, fatigue on awakening, and tender point score compared to placebo. There was no significant difference in pain improvement between patients taking amitriptyline alone or amitriptyline with naproxen. Scudds et al (1989) administered 36 patients with a low flexible dose $(<50 \mathrm{mg} / \mathrm{d})$ of amitriptyline for 10 weeks and found significant improvements in pain, tender point sensitivity and patient assessment of well-being compared with placebo. In a 12-week study 130 female FMS patients were randomized to receive amitriptyline $(25-37.5 \mathrm{mg} / \mathrm{d})$, the reversible monoamine oxidase inhibitor, moclobemide (450-600 mg), or placebo (Hannonen et al 1998). Various measures including general health, pain, sleep quality and quantity, and fatigue as estimated by visual analogue scales were significantly more improved in patients on amitriptyline than in the other groups. Moclobemide improved pain, but had no effect on other parameters including sleep. The tricyclic compound cyclobenzaprine, which differs from amitriptyline by only one double bond, is a muscle relaxant and not an antidepressant. It has also been shown to be effective in reducing the symptoms of FMS when administered at $10-40 \mathrm{mg} / \mathrm{d}$ at bedtime in randomized controlled trials lasting 6-12 weeks (Carette et al 1994; Bennett et al 1998; Tofferi et al 2004). A longer study (Carette et al 1994), which followed 208 patients treated with amitriptyline, cyclobenzaprine, or placebo for 6 months reported significant clinical improvement for both tricyclic drugs although initial improvement was lost at 6 months.

Two meta-analyses have concluded that tricyclic antidepressants (amitriptyline, maprotiline, chlorimipramine, dothiepin) were better than placebo in the treatment of FMS (Table 1). From 16 randomized, placebo-controlled trials involving TCAs, Arnold et al (2000) found that 9 were appropriate for data extraction. Overall, the quality of the studies was good. Compared with placebo, effect sizes of TCAs, calculated for patient and physician global assessment, pain, fatigue, sleep, tenderness, stiffness, were significantly larger than zero. Quality of sleep was the most improved measurement, whereas stiffness and tenderness had only modest improvement. There was a significant clinical response in $25 \%-37 \%$ of patients although the overall degree of efficacy was modest in most studies. A second meta-analysis found that the odds ratio for improvement with antidepressants (mainly TCAs but also including some other antidepressants) was 4.2 (95\% confidence interval, 2.6-6.8), and pain, sleep, fatigue, and sense of well-being were improved, but there was no improvement in trigger points (O’Malley et al 2000).

Thus there is strong evidence for efficacy of the TCAs especially amitriptyline in FMS (Goldenberg et al 2004; Offenbaecher and Ackenheil 2005). It should be noted, however, that the effect size of all the studies was small. The 
Table I Principal placebo-controlled trials of antidepressants in the treatment of fibromyalgia syndrome

\begin{tabular}{|c|c|c|c|c|c|c|}
\hline Study & $\begin{array}{l}\text { Treatment } \\
\text { groups }\end{array}$ & $\begin{array}{l}\text { Daily dose } \\
\text { (mg/d) }\end{array}$ & $\mathbf{n}$ & Design & Duration & Outcome \\
\hline \multirow[t]{2}{*}{ Carrette et al 1986} & amitriptyline & 50 & 27 & parallel & 9 wks & $\mathrm{AMI}>\mathrm{PL}$ \\
\hline & placebo & & 32 & & & \\
\hline \multirow[t]{2}{*}{ Goldenberg et al 1986} & amitriptyline & 25 & 16 & parallel & 6 wks & $\mathrm{AMI}>\mathrm{PL}$ \\
\hline & placebo & & 16 & & & \\
\hline \multirow[t]{3}{*}{ Bibolotti et al 1986} & maprotiline & 75 & 37 & cross-over & $3 \times 3$ wks & Inconclusive, very high drop out \\
\hline & chlorimipramine & 75 & & & & \\
\hline & placebo & & & & & \\
\hline \multirow[t]{2}{*}{ Caruso et al 1987} & dothiepin & 75 & 27 & parallel & 8 wks & DOT > PL \\
\hline & placebo & & 25 & & & \\
\hline \multirow[t]{2}{*}{ Scudds et al 1989} & amitriptyline & 50 & 36 & cross-over & $2 \times 4$ wks & $\mathrm{AMI}>\mathrm{PL}$ \\
\hline & placebo & & & & & \\
\hline Jaeschke et al I99I & amitriptyline & $5-50$ & 23 & N-of-I & & $25 \%$ significant positive response \\
\hline \multirow[t]{3}{*}{ Carrette et al 1994} & amitriptyline & 50 & 98 & parallel & 26 wks & $\mathrm{AMI}=\mathrm{CYC}>\mathrm{PL}$ \\
\hline & cyclobenzaprine & 30 & 86 & & & \\
\hline & placebo & & 96 & & & \\
\hline \multirow[t]{2}{*}{ Wolfe et al 1994} & fluoxetine & 20 & 21 & parallel & 6 wks & FLU = PL \\
\hline & placebo & & 21 & & & \\
\hline \multirow[t]{2}{*}{ Norregaard et al 1995} & citalopram & $20-40$ & 22 & parallel & 8 wks & $\mathrm{CIT}=\mathrm{PL}$ \\
\hline & placebo & & 21 & & & \\
\hline \multirow[t]{2}{*}{ Ginsberg et al 1996} & amitriptyline & 25 & 24 & parallel & 8 wks & $\mathrm{AMI}>\mathrm{PL}$ \\
\hline & placebo & & 22 & & & \\
\hline \multirow[t]{5}{*}{ Goldenberg et al 1996} & amitriptyline + PL & 25 & 19 & Cross-over & $4 \times 6$ wks & $\mathrm{FLU}+\mathrm{AMI}>\mathrm{AMI}=\mathrm{FLU}>\mathrm{PL}$ \\
\hline & amitriptyline + & $25+20$ & & & & \\
\hline & fluoxetine & & & & & \\
\hline & fluoxetine $+P L$ & 20 & & & & \\
\hline & placebo & & & & & \\
\hline \multirow[t]{3}{*}{ Hannonen et al 1998} & amitriptyline & $23-37.5$ & 43 & parallel & 12 wks & $\mathrm{AMI}>\mathrm{MOC}=\mathrm{PL}$ \\
\hline & moclobemide & $450-600$ & 42 & & & \\
\hline & placebo & & 45 & & & \\
\hline \multirow[t]{2}{*}{ Anderberg et al 2000} & citalopram & $20-40$ & 21 & parallel & 16 wks & $\mathrm{CIT}=\mathrm{PL}$ \\
\hline & placebo & & 19 & & & \\
\hline \multirow[t]{2}{*}{ Arnold et al 2002} & fluoxetine & $20-80$ & 32 & parallel & 12 wks & $\mathrm{FLU}>\mathrm{PL}$ \\
\hline & placebo & & 28 & & & \\
\hline \multirow[t]{2}{*}{ Zijlstra et al 2002} & venlafaxine & 75 & 45 & parallel & 6 wks & VEN = PL \\
\hline & placebo & & 45 & & & \\
\hline \multirow[t]{2}{*}{ Purcell et al 2004} & paroxetine & $12.5-62.5$ & 58 & parallel & 12 wks & Globally PAR > PL but no effect \\
\hline & placebo & & 58 & & & on VAS pain scores \\
\hline \multirow[t]{2}{*}{ Arnold et al 2004} & duloxetine & 120 & 104 & parallel & 12 wks & $\mathrm{DUL}>\mathrm{PL}$ \\
\hline & placebo & & 103 & & & \\
\hline \multirow[t]{3}{*}{ Arnold et al 2005} & duloxetine & 60 & 118 & parallel & 12 wks & $\operatorname{DUL}(60)=\operatorname{DUL}(120)>P L$ \\
\hline & duloxetine & 120 & 116 & & & \\
\hline & placebo & & 120 & & & \\
\hline \multirow[t]{3}{*}{ Gendreau et al 2005} & milnacipran (od) & 200 & 51 & parallel & 12 wks & $\mathrm{MIL}>\mathrm{PL}$ \\
\hline & milnacipran (bid) & 200 & 46 & & & \\
\hline & placebo & & 28 & & & \\
\hline
\end{tabular}

Note: Bold print highlights the absence of effect.

Abbreviations: AMI, amitriptyline; CIT, citalopram; CYC, cyclobenzaprine; DOT, dothiepin; DUL, duloxetine; FLU, fluoxetine; MIL, milnacipran; MOC, moclobemide; PAR, paroxetine; PL, placebo;VEN, venlafaxine; wks, weeks. 
doses used were considerably lower than those considered necessary for an optimal effect in major depression and no studies of amitriptyline have carried out a dose-range study. Would higher doses of TCAs produce larger therapeutic effects? Would the greater side-effects to be expected at higher doses be acceptable? Clearly more effective and better tolerated drugs are clearly needed. This line of thinking led to testing the selective serotonin reuptake inhibitors (SSRI) in FMS.

\section{Selective serotonin reuptake inhibitors}

\section{Fluoxetine}

In a 6-week double-blind placebo-controlled study, 42 women suffering from FMS were randomized to receive either placebo or fluoxetine at $20 \mathrm{mg} / \mathrm{d}$ (Wolfe et al 1994). At end-point fluoxetine was ineffective on all measures except depression scores. A better outcome was found, however, in another study using higher doses. Sixty women outpatients with FMS were randomly assigned to receive fluoxetine (10-80 mg/d) or placebo for 12 weeks in a double-blind, parallelgroup, flexible-dose study. The mean dose of fluoxetine administered was $45 \pm 25 \mathrm{mg} / \mathrm{d}$, which is a higher dose than that usually prescribed to depressed patients, significantly improved the Fibromyalgia Impact Questionnaire (FIQ) total score, the FIQ pain score, and the FIQ fatigue and depression scores (Arnold et al 2002). No statistically significant difference was found, however, for pain at tender points and total myalgic scores between the fluoxetine group and the placebo group.

A 6-week, randomized, double-blind, crossover study evaluated the effect of fluoxetine $(20 \mathrm{mg})$, amitriptyline (25 mg), a combination of fluoxetine and amitriptyline, or placebo, in 19 patients with fibromyalgia (Goldenberg et al 1996). Both drugs improved scores on the FIQ and on the VAS for pain, global well-being, and sleep disturbances, and the combination of the 2 treatments worked better than either medication alone.

Similarly, pain intensity, the number of painful tender points, tender points index and morning stiffness were improved with fluoxetine $(20 \mathrm{mg} / \mathrm{d})$ combined with cyclobenzaprine $(10 \mathrm{mg} /$ d) in a 12-week study of 21 females with FMS (Cantini et al 1994) compared with cyclobenzaprine alone.

All of the above studies are small and can only be considered suggestive. It appears possible that doses higher than those usually used for depression or combination of fluoxetine with other active compounds may result in some relief of symptoms in patients with FMS.

\section{Citalopram}

Two randomized, double blind, placebo-controlled studies have shown that citalopram was ineffective. In the first, 22 patients with fibromyalgia were treated with citalopram at a dose of $20 \mathrm{mg} / \mathrm{d}$ while 21 received placebo, for 4 weeks (Norregaard et al 1995). If the subjects did not show a marked improvement after 4 weeks the dosage of citalopram was increased to $40 \mathrm{mg}$ for a further 4 weeks. At the end of treatment ( 8 weeks) no differences were observed between the groups. The second study included 40 female patients, 21 patients in the citalopram (20-40 mg/d) groups, and 19 in the placebo group (Anderberg et al 2000). Citalopram was ineffective on all measures except pain visual analogue scale at 2 months but not at the 4-month end-point. Measurement of pain with the FIQ also showed some significant differences at the end of the trial. Taken together these trials give little indication of any utility of citalopram in the treatment of FMS.

\section{Paroxetine}

There are no published studies of paroxetine in FMS. A doubleblind, placebo-controlled, 12-week trial with 116 patients has been presented as a poster (Purcell et al 2004), which is not yet published in full. Response was defined as an improvement of $25 \%$ or more on the total FIQ score rather than the more usual 50\%. Using this definition the study found significantly more responders with controlled release paroxetine (12.5-62.5 mg/d, mean dose $32.3 \mathrm{mg} / \mathrm{d}$ ) than with placebo at the end of the study. There were, however, no significant difference between paroxetine and placebo on the VAS pain scores.

\section{Sertraline}

A 6-month comparative, prospective, randomized study of 70 fibromyalgia female patients compared the efficacy of sertraline ( $50 \mathrm{mg} / \mathrm{d}$ for 6 months, $\mathrm{n}=36$ ) versus physical therapy (15 sessions of $1 \mathrm{~W} / \mathrm{cm}^{2}$ ultrasonography on the cervical trigger points plus physical therapy, $\mathrm{n}=34$ ). Patients treated with sertraline had a better outcome in terms of pain, morning stiffness, and sleep disorders, than the group treated with ultrasonography and physical therapy (Gonzalez-Viejo et al 2005).

\section{Fluvoxamine}

No published placebo-controlled trials are available so far.

The results of studies on SSRIs have, in general, been disappointing. Efficacy, if it exists, appears to be quite modest 
and the evidence, at best, inconsistent. Consequently this class of drugs is considered by many to be less efficacious than TCAs (Littlejohn and Guymer 2006).

\section{Selective norepinephrine reuptake inhibitors}

A possible explanation for the decreased efficacy of the SSRIs compared with the TCAs could reside in the absence of noradenergic activity of the former. Reboxetine is a specific inhibitor of the reuptake of NE, used in a number of countries as an antidepressant (Preskorn 2004).

\section{Reboxetine}

In a case series, depressed patients with FMS experienced relief of pain symptoms when treated with the noradrenergic antidepressant reboxetine. Significant relief of pain occurred before any significant improvement in mood symptoms (Krell et al 2005).

Obviously further studies with selective NE reuptake inhibitors such as reboxetine or atomoxetine are required before any conclusions can be drawn.

\section{Serotonin and norepinephrine reuptake inhibitors \\ Venlafaxine}

Although several open studies of venlafaxine in the treatment of FMS have suggested a reduction of FMS symptoms (Dwight et al 1998; Dryson 2000; Sayar et al 2003), a 6-week, placebo-controlled trial has demonstrated that venlafaxine (75 $\mathrm{mg} / \mathrm{d})(\mathrm{n}=45)$ was ineffective on pain measured with a visual analogue scale (Zijlstra et al 2002) compared to placebo ( $\mathrm{n}=$ 45). It is important to note here that at the dose of venlafaxine used in this study only the reuptake of 5-HT is likely to be inhibited. There have been no studies at higher doses, which are likely to inhibit both monoamine transporters.

\section{Duloxetine}

In a randomized, double blind, placebo-controlled trial conducted on 207 subjects (89\% women) with FMS, with or without current major depressive disorder, subjects were assigned to receive duloxetine $60 \mathrm{mg}$ twice a day $(\mathrm{n}=104)$, which is a higher dose than the antidepressant dose, or placebo $(\mathrm{n}=103$ ) for 3 months (Arnold et al 2004b). Duloxetine was found to be better than placebo in FIQ total score and the FIQ subscore, stiffness, but not in the other FIQ subscores (pain, fatigue, morning tiredness). There were more responders (defined as a reduction of at least $50 \%$ in the self-rating Brief
Pain Inventory average pain severity score) with duloxetine than with placebo. This reduction was significant only in female patients.

In a second study (Arnold et al 2005) the efficacy of duloxetine in FMS was assessed in a 12-week, randomized, double-blind, placebo-controlled trial in 354 female patients with FMS. Patients received duloxetine $60 \mathrm{mg}$ once daily (qd) ( $\mathrm{n}=118)$, duloxetine $60 \mathrm{mg}$ twice daily (bid) $(\mathrm{n}=116)$, or placebo $(\mathrm{n}=120)$. There were significantly more responders (defined in this study as a reduction of at least $30 \%$ on the Brief Pain Inventory average pain severity score) in both duloxetinetreated groups compared with placebo (duloxetine $60 \mathrm{mg} \mathrm{qd}$, $55 \%$ responders, $\mathrm{p}<0.001$; duloxetine $60 \mathrm{mg}$ bid, $54 \%, \mathrm{p}=$ 0.002 ; placebo, $33 \%$ responders). Compared with patients on placebo, patients treated with duloxetine $60 \mathrm{mg}$ qd or duloxetine $60 \mathrm{mg}$ bid also had significantly greater improvement on a number of other outcome measures. In both studies, duloxetine was well tolerated, and its effect on FMS symptoms was independent of its effect on mood (Arnold et al 2004b, 2005). There was no major difference between the two doses (60 and $120 \mathrm{mg} / \mathrm{d})$.

\section{Milnacipran}

An open study (Nagaoka et al 2004) of the effect of milnacipran (30-100 mg/d) on 20 patients with FMS found that pain and general symptomatology were significantly improved at the end of the study.

In a double blind, placebo-controlled trial 125 patients with FMS were randomized, in a 3:3:2 ratio, to receive milnacipran twice daily, milnacipran once daily, or placebo (Gendreau et al 2005). Two weeks baseline were followed by 4 weeks flexible dose escalation (up to $200 \mathrm{mg} / \mathrm{d}$ ), followed by a further 8 weeks at a constant fixed dose, with $81 \%$ of once daily (qd) and $92 \%$ of twice daily (bid) patients reaching the target dose of 200 $\mathrm{mg} / \mathrm{d}$. The primary end-point was reduction of global pain, reported by using an electronic diary. The mean weekly pain intensity decreased with time in the placebo group and both milnacipran groups but the reduction was significantly greater with twice-daily milnacipran than with placebo. Over $70 \%$ of patients treated with milnacipran, either bid or qd, reported overall improvement compared with $38 \%$ of those in the placebo group $(\mathrm{p}<0.01)$. Of patients treated twice daily with milnacipran, $37 \%$ reported at least $50 \%$ reduction in pain intensity, compared with $14 \%$ of placebo-treated patients $(p<0.05)$. Fatigue, stiffness, and global well-being assessed by using the FIQ subscales, were significantly improved in both milnacipran groups, compared with the placebo group. Response rates for patients receiving milnacipran were similar 
in patients with and without comorbid depression, whereas patients with depression had a greater response to placebo than non-depressed patients. The greatest drug-placebo difference was therefore found in the non-depressed patients. Milnacipran was well tolerated and $84 \%$ of all patients treated with milnacipran escalated to the highest dose (200 mg/day) with no tolerability problems.

\section{Other dual-acting compounds}

\section{Mirtazapine}

Mirtazapine acts primarily as a $\alpha_{2}$-adrenergic receptor antagonist and as such has indirect effects on both serotonergic and noradrenergic neurotransmission (Szegedi and Schwertfeger 2005). It is thus considered to be a dual acting antidepressant albeit by a mechanism different from the SNRIs. In 26 patients with FMS who completed a 6-week open study with mirtazapine, $10(38 \%)$ responded with a reduction of at least $40 \%$ of the initial levels of pain, fatigue and sleep disturbances (Samborski et al 2004). However, since this was an open trial, double-blind placebo-controlled studies are required to confirm these results.

\section{Conclusion}

Thus theoretical considerations and empirical observations suggested the utility of antidepressants in the treatment of FMS. Extensive clinical trials have produced convincing evidence for the efficacy of TCAs (Table 1) as an effective treatment option for patients suffering from FMS, whereas the usefulness of SSRIs is unclear. Among the TCAs tested, amitriptyline has been most studied and its efficacy has been unequivocally demonstrated even though its effect size is limited. The SNRIs, duloxetine and milnacipran, have also demonstrated a clinical benefit in placebo-controlled trials. Venlafaxine, on the other hand, was inactive (Zijlstra et al 2002). At the dose used, $75 \mathrm{mg} / \mathrm{d}$, however, venlafaxine would be expected only to block the uptake of 5-HT and thus for this study venlafaxine should be considered as a SSRI.

A characteristic feature common to amitriptyline, duloxetine, and milnacipran, which differentiates them from the SSRIs is their ability to block the reuptake of both NE and 5-HT. It has been suggested that this dual mechanism of action could be involved in the relief of pain and other symptoms in FMS (Briley and Moret 2003).

There is evidence for modified serotonergic and noradrenergic neurotransmission in FMS. The evidence for modifications of the 5-HT system, however, is more extensive than that for NE neurotransmission.

Reduced levels of the 5-HT metabolite, 5-hydroxyindole acetic acid, have been reported in the cerebrospinal fluid (CSF) of FMS patients compared with controls (Houvenagel et al 1990; Russell et al 1992a,b; Legangneux et al 2001). Serum levels of 5-HT and tryptophan are similarly lower in patients with FMS than in control subjects (Russell et al 1989; Alnigenis and Barland 2001). An increased density of 5-HT receptors on platelets in patients with FMS (Russell et al 1992b) and abnormal transport of serum tryptophan (Yunus et al 1990), which have also been reported, indicate a general disturbance of serotonergic neurotransmission. Interestingly, however, tryptophan depletion in FMS patients had no effect on their pain severity (Schwarz et al 2003).

Evidence for a noradrenergic disturbance in FMS includes decreased levels of the NE metabolite, 3-methoxy, 4-hydroxy phenylglycol (MHPG), in FMS patients (Russell et al 1992a; Legangneux et al 2001) although Yunus et al (1992) found no changes in plasma and urinary catecholamines in FMS patients. Direct injection of NE causes pain in about $80 \%$ of FMS patients compared with only about $10 \%$ of patients suffering from rheumatoid arthiritis, used as controls (Martinez-Lavin et al 2002). In addition the intensity of the induced pain in FMS patients was greater than the control groups. On the basis of these data the authors suggested that FMS might be the result of a sympathetic hyperactivity.

Evidence for an important role of NE in pain relief in general has come from a study in non-depressed patients with chronic back pain which showed that the NE selective antidepressant, maprotiline, produced significantly more pain relief than either placebo or the SSRI, paroxetine (Atkinson et al 1999).

Considerable animal data also confirm the involvement of both 5-HT and NE in the pathogenesis of chronic pain and its relief by antidepressants (Tura and Tura 1990; Sierralta et al 1995; Fishbain et al 2000).

The involvement of the two monoamine systems in the control of pain has a clear neuroanatomical basis. Both serotonergic and noradrenergic systems have projections ascending to various parts of the brain and descending to the spinal cord. Serotonergic cell bodies, located in the raphe nucleus, send projections to various parts of the brain such as the frontal cortex, basal ganglia, limbic areas, and hypothalamus where they mediate specific functions (control of mood, movement, anxiety) and behaviors (eating, sexual activity, feeling of pleasure). The cell bodies of the noradrenergic neurons, located in the locus coeruleus, project 
to the frontal cortex, the limbic areas and the hypothalamus, and also to specific areas in the frontal cortex where they regulate attention and cognition. In addition to these ascending serotonergic and noradrenergic pathways, neurons in the raphe nucleus and the locus coeruleus also project to the spinal cord (Wall and Melzack 1999) where they serve to inhibit input from the periphery. There is thus an involvement of both 5-HT and NE in the mediation of endogenous analgesic mechanisms via the descending inhibitory pain pathways in the brain and spinal cord (Basbaum and Fields 1978; 1984; Clark and Proudfit 1993; Millan 2002). A dysfunction of these 5-HT- and NE-mediated descending pain-inhibitory pathways can therefore result in heightened sensitivity to pain (hyperalgesia) and even in the induction of pain (allodynia), and is a potential mechanism for the pain experienced by patients with FMS.

It could be argued that the FMS patients treated with antidepressants feel relief from pain and other symptoms as a result of the effect of these drugs on their depression. It has been shown, however, that the effect of duloxetine is similar in patients with FMS with or without depression (Arnold et al 2004) and that the effect of milnacipran is greater in nondepressed FMS patients (Gendreau et al 2005). In addition, TCAs and SNRIs are effective in different chronic pain syndromes independently of the presence of depression (Salerno et al 2002; Briley 2004).

It is now generally accepted (Littlejohn and Guymer 2006) that SSRIs are not as effective for overall improvement of FMS symptoms as drugs that block the reuptake of both 5-HT and NE in a relatively balanced way. Among the antidepressants, duloxetine and milnacipran, which are both undergoing active clinical development for an indication in FMS, appear to provide the best therapeutic option. They have efficacy which is, at least, similar to amitriptyline and a far superior tolerability. How these compounds will compare with the non-antidepressant, pregabalin, which is also in development in this indication (Crofford et al 2005), remains to be seen.

\section{References}

Adler GK, Kinsley BT, Hurwitz S, et al. 1999. Reduced hypothalamicpituitary and sympathoadrenal responses to hypoglycemia in women with fibromyalgia syndrome. Am J Med, 106:534-43.

Alnigenis MN, Barland P. 2001. Fibromyalgia syndrome and serotonin. Clin Exp Rheumatol, 19:205-10.

Anderberg UM, Marteinsdottir I, von Knorring L. 2000. Citalopram in patients with fibromyalgia - a randomized, double-blind, placebo-controlled study. Eur J Pain, 4:27-35.
Arnold LM, Keck PE Jr, Welge JA. 2000. Antidepressant treatment of fibromyalgia. A meta-analysis and review. Psychosomatics, 41:104-13.

Arnold LM, Hess EV, Hudson JI, et al. 2002. A randomized, placebocontrolled, double-blind, flexible-dose study of fluoxetine in the treatment of women with fibromyalgia. Am J Med, 112:191-7.

Arnold LM, Hudson JI, Hess EV, et al. 2004a. Family study of fibromyalgia. Arthritis Rheum, 50:944-52.

Arnold LM, Lu Y, Crofford LJ, et al. 2004b. A double-blind, multicenter trial comparing duloxetine with placebo in the treatment of fibromyalgia patients with or without major depressive disorder. Arthritis Rheum, 50:2974-84.

Arnold LM, Rosen A, Pritchett YL, et al. 2005. A randomized, doubleblind, placebo-controlled trial of duloxetine in the treatment of women with fibromyalgia with or without major depressive disorder. Pain, 119:5-15.

Arroyo JF, Cohen ML. 1993. Abnormal responses to electrocutaneous stimulation in fibromyalgia. $J$ Rheumatol, 20:1925-31.

Atkinson JH, Slater MA, Wahlgren DR, et al. 1999. Effects of noradrenergic and serotonergic antidepressants on chronic low back pain intensity. Pain, 83:137-45.

Barkhuizen A. 2002. Rational and targeted pharmacologic treatment of fibromyalgia. Rheum Dis Clin North Am, 28:261-90.

Basbaum AI, Fields HL. 1978. Endogenous pain control mechanisms: review and hypothesis. Ann Neurol, 4:451-62.

Basbaum AI, Fields HL. 1984. Endogenous pain control systems: brainstem spinal pathways and endorphin circuitry. Ann Rev Neurosci, 7:309-38.

Bennett RM. 1999. Emerging concepts in the neurobiology of chronic pain: evidence of abnormal sensory processing in fibromyalgia. Mayo Clin Proc, 74:385-98.

Bennett RM. 2005. Fibromyalgia: present to future. Curr Rheumatol Rep, 7:371-6.

Bennett RM, Gatter RA, Campbell SM, et al. 1998. A comparison of cyclobenzaprine and placebo in the management of fibrositis. A double-blind controlled study. Arthritis Rheum, 31:1535-42.

Bennett RM, Schein J, Kosinski MR, et al. 2005. Impact of fibromyalgia pain on health-related quality of life before and after treatment with tramadol/acetaminophen. Arthritis Rheum, 53:519-27.

Biasi G, Manca S, Manganelli S, et al. 1998. Tramadol in the fibromyalgia syndrome: a controlled clinical trial versus placebo. Int J Clin Pharmacol Res, 18:13-19.

Bibolotti E, Borghi C, Pasculli E, et al. 1986. A double-blind comparison of maprotiline, chloriimipramine and placebo. Clin Trials $J$ 23:269-80.

Bradley LA, McKendree-Smith NL, Alarcon GS, et al. 2002. Is fibromyalgia a neurologic disease? Curr Pain Headache Rep, $6: 106-14$.

Briley M. 2004. Clinical experience with dual action antidepressants in different chronic pain syndromes. Hum Psychopharmacol, 19 Suppl 1:S21-5.

Briley M, Moret C. 2003. Fibromyalgia syndrome: an overview of potential drug targets. Idrugs, 6:668-73.

Burckhardt CS, Clark SR, Bennett RM. 1991. The fibromyalgia impact questionnaire: development and validation. J Rheumatol, 18:728-33.

Buskila D, Neumann L. 2002. The development of widespread pain after injuries. J Musculoskel Pain, 10:261-7.

Buskila D, Neumann L, Press J. 2005. Genetic factors in neuromuscular pain. CNS Spectr, 10:281-4.

Cantini F, Bellandi F, Niccoli L, et al. 1994. Fluoxetine combined with cyclobenzaprine in the treatment of fibromyalgia, Minerva Med, 85:97-100

Carette S, McCain GA, Bell DA, et al. 1986. Evaluation of amitriptyline in primary fibrositis. A double-blind, placebo-controlled study. Arthritis Rheum, 29:655-9. 
Carette S, Bell MJ, Reynolds WJ, et al. 1994. Comparison of amitriptyline, cyclobenzaprine, and placebo in the treatment of fibromyalgia. A randomized, double-blind clinical trial. Arthritis Rheum, 37:32-40.

Caruso I, Sarzi Puttini PC, Boccassini L, et al. 1987. Double-blind study of dothiepin versus placebo in the treatment of primary fibromyalgia syndrome. J Int Med Res, 15:154-9.

Catley D, Kaell AT, Kirschbaum C. et al. 2000. A naturalistic evaluation of cortisol secretion in persons with fibromyalgia and rheumatoid arthritis. Arthritis Care Res, 13:51-61.

Clark FM, Proudfit HK. 1993. The projections of noradrenergic neurons in the A5 catecholamine cell group to the spinal cord in the rat: anatomical evidence that A5 neurons modulate nociception. Brain Res, 616:200-10.

Cohen H, Buskila D, Neumann L, et al. 2002. Confirmation of an association between fibromyalgia and serotonin transporter promoter region (5-HTTLPR) polymorphism, and relationship to anxiety-related personality traits. Arthritis Rheum, 46:8457 .

Crofford LJ. 1998. The hypothalamic-pituitary-adrenal stress axis in fibromyalgia and chronic fatigue syndrome. $Z$ Rheumatol, 57 Suppl 2:67-71.

Crofford LJ, Clauw DJ. 2002. Fibromyalgia: where are we a decade after the American College of Rheumatology classification criteria were developed? Arthritis Rheum, 46:1136-18.

Crofford LJ, Engleberg NC, Demitrack MA. 1996. Neurohormonal perturbations in fibromyalgia. Baillieres Clin Rheumatol, 10:365-78.

Crofford LJ, Rowbotham MC, Mease PJ, et al. 2005. Pregabalin for the treatment of fibromyalgia syndrome: results of a randomized, double-blind, placebo-controlled trial. Arthritis Rheum, 52: $1264-1273$.

Dryson E. 2000. Venlafaxine and fibromyalgia. $N Z$ Med $J$, 113:87.

Dunkl PR, Taylor AG, McConnell GG, et al. 2000. Responsiveness of fibromyalgia clinical trial outcome measures. $J$ Rheumatol, 27:2683-91.

Dwight MM, Arnold LM, O'Brien H, et al. 1998. An open clinical trial of venlafaxine treatment of fibromyalgia. Psychosomatics, 39:14-17.

Epstein SA, Kay G, Clauw D, et al. 1999. Psychiatric disorders in patients with fibromyalgia. A multicenter investigation. Psychosomatics, 40:57-63.

Fishbain DA, Cutler R, Rosomoff HL, et al. 2000. Evidence-based data from animal and human experimental studies on pain relief with antidepressants: a structured review. Pain Med, 1:310-16.

Fries E, Hesse J, Hellhammer J, et al. 2005. A new view on hypocortisolism. Psychoneuroendocrinology, 30:1010-16.

Geisser ME, Casey KL, Brucksch CB, et al. 2003. Perception of noxious and innocuous heat stimulation among healthy women and women with fibromyalgia: association with mood, somatic focus, and catastrophizing. Pain, 102:243-50.

Gendreau RM, Thorn MD, Gendreau JF, et al. 2005. Efficacy of milnacipran in patients with fibromyalgia. J Rheumatol, 32:1975-85.

Ginsberg F, Mancaux A, Joos E, et al. 1996. A randomised placebocontrolled trial of sustained release amitriptyline in primary fibromyalgia. J Muscoskeletal Pain, 4:37-47.

Goldenberg DL, Felson DT, Dinerman H. 1986. A randomized, controlled trial of amitriptyline and naproxen in the treatment of patients with fibromyalgia. Arthritis Rheum, 29:1371-7.

Goldenberg D, Mayskiy M, Mossey C, et al. 1996. A randomized, double-blind crossover trial of fluoxetine and amitriptyline in the treatment of fibromyalgia. Arthritis Rheum, 39:1852-1859.

Goldenberg DL, Burckhardt C, Crofford L. 2004. Management of fibromyalgia syndrome. JAMA, 292:2388-95.

Gonzalez-Viejo MA, Avellanet M, Hernandez-Morcuende MI. 2005. A comparative study of fibromyalgia treatment: ultrasonography and physiotherapy versus sertraline treatment. Ann Readapt Med Phys, 48:610-15.
Gracely RH, Petzke F, Wolf JM, et al. 2002. Functional magnetic resonance imaging evidence of augmented pain processing in fibromyalgia. Arthritis Rheum, 46:1333-43.

Granges G, Littlejohn G. 1993. Pressure pain threshold in pain-free subjects, in patients with chronic regional pain syndromes, and in patients with fibromyalgia syndrome. Arthritis Rheum, $36: 642-6$

Graven-Nielsen T, Sorensen J, Henriksson KG, et al. 1999. Central hyperexcitability in fibromyalgia. $J$ Musculoskel Pain, 7:261-71.

Gur A, Cevik R, Sarac AJ, et al. 2004. Hypothalamic-pituitary-gonadal axis and cortisol in young women with primary fibromyalgia: the potential roles of depression, fatigue, and sleep disturbance in the occurrence of hypocortisolism. Ann Rheum Dis, 63: $1504-6$.

Hannonen P, Malminiemi K, Yli-Kerttula U, et al. 1998. A randomized, double-blind, placebo-controlled study of moclobemide and amitriptyline in the treatment of fibromyalgia in females without psychiatric disorder. Br J Rheumatol, 37:1279-86.

Hawley DJ, Wolfe F. 1991. Pain, disability, and pain/disability relationships in seven rheumatic disorders: a study of 1,522 patients. J Rheumatol, 18:1552-7.

Henriksson KG. 2003. Fibromyalgia - from syndrome to disease. Overview of pathogenetic mechanisms. $J$ Rehabil Med, 41(Suppl):89-94.

Herrero JF, Laird JM, Lopez-Garcia JA. 2000. Wind-up of spinal cord neurones and pain sensation: much ado about something? Prog Neurobiol, 61:169-203.

Houvenagel E, Forzy G, Leloire O, et al. 1990. Cerebrospinal fluid monoamines in primary fibromyalgia. Rev Rhum Mal Osteoartic, $57: 21-3$

Hudson JI, Goldenberg DL, Pope HG Jr, et al. 1992. Comorbidity of fibromyalgia with medical and psychiatric disorders. Am J Med, 92:363-7.

Hudson JI, Hudson MS, Pliner LF, et al. 1985. Fibromyalgia and major affective disorder: a controlled phenomenology and family history study. Am J Psychiatry, 142:441-6.

Hudson JI, Pope HG Jr. 1996. The relationship between fibromyalgia and major depressive disorder. Rheum Dis Clin North Am, 22:285-303.

Jaeschke R, Adachi J, Guyatt G, et al. 1991. Clinical usefulness of amitriptyline in fibromyalgia: the results of $23 \mathrm{~N}$-of- 1 randomized controlled trials. J Rheumatol, 18:447-51.

Kassam A, Patten SB. 2006. Major depression, fibromyalgia and labour force participation: a population-based cross-sectional study. $B M C$ Musculoskelet Disord, 7:4.

Kranzler JD, Gendreau JF, Rao SG. 2002. The psychopharmacology of fibromyalgia: a drug development perspective. Psychopharmacol Bull, 36:165-213.

Krell HV, Leuchter AF, Cook IA, et al. 2005. Evaluation of reboxetine, a noradrenergic antidepressant, for the treatment of fibromyalgia and chronic low back pain. Psychosomatics, 46:379-84.

Kurland JE, Coyle WJ, Winkler A, Zable E. 2006. Prevalence of irritable bowel syndrome and depression in fibromyalgia. Dig Dis Sci, 51:454-60.

Legangneux E, Mora JJ, Spreux-Varoquaux O, et al. 2001. Cerebrospinal fluid biogenic amine metabolites, plasma-rich platelet serotonin and $[3 \mathrm{H}]$ imipramine reuptake in the primary fibromyalgia syndrome. Rheumatology (Oxford), 40:290-6.

Leventhal LJ. 1999. Management of fibromyalgia. Ann Intern Med, 131:850-8.

Littlejohn GO, Guymer EK. 2006. Fibromyalgia syndrome: which antidepressant drug should we choose? Curr Pharm Des, 12:3-9.

Martinez-Lavin M, Vidal M, Barbosa RE, et al. 2002. Norepinephrineevoked pain in fibromyalgia. A randomized pilot study. $B M C$ Musculoskelet Disord, 3:2-5.

Mease P. 2005. Fibromyalgia syndrome: review of clinical presentation, pathogenesis, outcome measures, and treatment. J Rheumatol, 75(Suppl):6-21. 
McBeth J, Chiu YH, Silman AJ, et al. 2005. Hypothalamic-pituitaryadrenal stress axis function and the relationship with chronic widespread pain and its antecedents. Arthritis Res Ther, 7:R992R1000.

Millan MJ. 2002. Descending control of pain. Prog Neurobiol, 66:355-474.

Moldofsky H, Scarisbrick P, England R, et al. 1975. Musculosketal symptoms and non-REM sleep disturbance in patients with "fibrositis syndrome" and healthy subjects. Psychosom Med, $37: 341-51$.

Mountz JM, Bradley LA, Modell JG, et al. 1995. Fibromyalgia in women. Abnormalities of regional cerebral blood flow in the thalamus and the caudate nucleus are associated with low pain threshold levels. Arthritis Rheum, 38:926-38.

Nagaoka S, Ohno M, Sekiguchi A. 2004. An open-label clinical trial of milnacipran in fibromyalgia syndrome with co-morbid depressive symptoms. Int $J$ Psychiatry Clin, Pract, 8:47-51.

Neeck G, Crofford LJ. 2000. Neuroendocrine perturbations in fibromyalgia and chronic fatigue syndrome. Rheum Dis Clin North Am, 26:989-1002.

Neumann L, Buskila D. 2003. Epidemiology of fibromyalgia. Curr Pain Headache Rep, 7:362-8.

Nicolodi M, Sicuteri F. 1996. Fibromyalgia and migraine, two faces of the same mechanism. Serotonin as the common clue for pathogenesis and therapy. Adv Exp Med Biol, 398:373-9.

Norregaard J, Volkmann H, Danneskiold-Samsoe B. 1995. A randomized controlled trial of citalopram in the treatment of fibromyalgia. Pain, 61:445-9.

Offenbaecher M, Ackenheil M. 2005. Current trends in neuropathic pain treatments with special reference to fibromyalgia. CNS Spectr, $10: 285-97$

Offenbaecher M, Bondy B, de Jonge S, et al. 1999. Possible association of fibromyalgia with a polymorphism in the serotonin transporter gene regulatory region. Arthritis Rheum, 42:2482-8.

Olsen NJ, Park JH. 1998. Skeletal muscle abnormalities in patients with fibromyalgia. Am J Med Sci, 315:351-8.

O'Malley PG, Balden E, Tomkins G, et al. 2000. Treatment of fibromyalgia with antidepressants: a meta-analysis. J Gen Intern Med, 15:659-66.

Owens MJ, Nemeroff CB. 1994. Role of serotonin in the pathophysiology of depression: focus on the serotonin transporter. Clin Chem, 40:288-95.

Preskorn SH. 2004. Reboxetine: a norepinephrine selective reuptake pump inhibitor. $J$ Psychiatr Pract, 10:57-63.

Price DD, Zhou Q, Moshiree B, Robinson ME, Verne GN. 2006. Peripheral and central contributions to hyperalgesia in irritable bowel syndrome. J Pain, 7:529-35.

Purcell C, Patkar A, Masand P, et al. 2004. Predictors of response to placebo-controlled, double-blind trial of paroxetine controlled release in fibromyalgia. Program and abstracts of the American Psychiatric Association Annual Meeting; May 1-6, 2004; New York, NY. Abstract NR361.

Rao SG, Clauw DJ. 2004. The management of fibromyalgia. Drugs Today (Barc), 40:539-54

Roizenblatt S, Moldofsky H, Benedito-Silva AA, et al. 2001. Alpha sleep characteristics in fibromyalgia. Arthritis Rheum, 44:222-30.

Russell IJ, Michalek JE, Vipraio GA, et al. 1989. Serum amino acids in fibrositis/fibromyalgia syndrome. Arthritis Rheum, 32 (Suppl 9):S70.

Russell IJ, Vaeroy H, Javors M, et al. 1992a. Cerebrospinal fluid biogenic amine metabolites in fibromyalgia/fibrositis syndrome and rheumatoid arthritis. Arthritis Rheum, 35:550-6.

Russell IJ, Michalek JE, Vipraio GA, et al. 1992b. Platelet 3H-imipramine uptake receptor density and serum serotonin levels in patients with fibromyalgia/fibrositis syndrome. J Rheumatol, 19:104-9.

Salerno SM, Browning R, Jackson JL. 2002. The effect of antidepressant treatment on chronic back pain: a meta-analysis. Arch Intern Med, 162:19-24.
Samborski W, Lezanska-Szpera M, Rybakowski JK. 2004. Open trial of mirtazapine in patients with fibromyalgia. Pharmacopsychiatry, $37: 168-70$.

Sarac AJ, Gur A. 2006. Complementary and alternative medical therapies in fibromyalgia. Curr Pharm Des, 12:47-57.

Sarzi-Puttini P, Rizzi M, Andreoli A, et al. 2002. Hypersomnolence in fibromyalgia syndrome. Clin Exp Rheumatol, 20:69-72.

Sayar K, Aksu G, Ak I, et al. 2003. Venlafaxine treatment of fibromyalgia. Ann Pharmacother, 37:1561-5.

Schwarz MJ, Offenbaecher M, Neumeister A, et al. 2003. Experimental evaluation of an altered tryptophan metabolism in fibromyalgia. Adv Exp Med Biol, 527:265-75.

Scudds RA, McCain GA, Rollman GB, et al. 1989. Improvements in pain responsiveness in patients with fibrositis after successful treatment with amitriptyline. J Rheumatol Suppl, 19:98-103.

Sierralta F, Pinardi G, Miranda HF. 1995. Effect of p-chlorophenylalanine and alpha-methyltyrosine on the antinociceptive effect of antidepressant drugs. Pharmacol Toxicol, 77:276-80.

Sorensen J, Graven-Nielsen T, Henriksson KG, et al. 1998. Hyperexcitability in fibromyalgia. $J$ Rheumatol, 25:152-55.

Staud R, Cannon RC, Mauderli AP, et al. 2003. Temporal summation of pain from mechanical stimulation of muscle tissue in normal controls and subjects with fibromyalgia syndrome. Pain, 102: $87-95$.

Staud R, Vierck CJ, Cannon RL, et al. 2001. Abnormal sensitization and temporal summation of second pain (wind-up) in patients with fibromyalgia syndrome. Pain, 91:165-75.

Sultan SM, Ioannou Y, Moss K, et al. 2002. Outcome in patients with idiopathic inflammatory myositis: morbidity and mortality. Rheumatology (Oxford), 41:22-26.

Szegedi A, Schwertfeger N. 2005. Mirtazapine: a review of its clinical efficacy and tolerability. Expert Opin Pharmacother, 6:631-41.

Tench C, Bentley D, Vleck V, et al. 2002. Aerobic fitness, fatigue, and physical disability in systemic lupus erythematosus. J Rheumatol, $29: 474-81$

Tofferi JK, Jackson JL, O’Malley PG. 2004. Treatment of fibromyalgia with cyclobenzaprine: A meta-analysis. Arthritis Rheum, 51:913.

Tura B, Tura SM. 1990. The analgesic effect of tricyclic antidepressants. Brain Res, 518:19-22.

Vandvik PO, Lydersen S, Farup PG. 2006. Prevalence, comorbidity and impact of irritable bowel syndrome in Norway. Scand $J$ Gastroenterol, 41:650-6.

Wall PD, Melzack R. 1999. Textbook of Pain 4th Edition, New York, Churchill Livingston.

Wallace DJ. 2006. Is there a role for cytokine based therapies in fibromyalgia? Curr Pharm Des, 12:17-22.

Weir PT, Harlan GA, Nkoy FL, et al. 2006. The incidence of fibromyalgia and its associated comorbidities: a population-based retrospective cohort study based on International Classification of Diseases, 9th Revision codes. J Clin Rheumatol. 12:124-8.

White KP, Harth M. 2001. Classification, epidemiology, and natural history of fibromyalgia. Curr Pain Headache Rep, 5:320-329.

Wolfe F, Smythe HA, Yunus MB, et al. 1990. The American College of Rheumatology 1990 Criteria for the Classification of Fibromyalgia. Report of the Multicenter Criteria Committee. Arthritis Rheum, 33:160-172

Wolfe F, Cathey MA, Hawley DJ. 1994. A double-blind placebo controlled trial of fluoxetine in fibromyalgia. Scand J Rheumatol, 23:255-259.

Yunus MB, Dailey JW, Masi AT, et al. 1990. Abnormal transport ratio of serum tryptophan in primary fibromyalgia. Arthritis Rheum, 33(9 Suppl):S55.

Yunus MB, Dailey JW, Aldag JC, et al. 1992. Plasma and urinary catecholamines in primary fibromyalgia: a controlled study. $J$ Rheumatol, 19:95-97.

Yunus MB. 1998. Genetic factors in fibromyalgia syndrome. Z Rheumatol, 57(Suppl 2):61-62. 
Zijlstra TR, Barendregt EJ, van de Laar MA. 2002. Venlafaxine in fibromyalgia: results of a randomized, placebo-controlled, doubleblind trial. Arthritis Rheum, 46(suppl 9):S105. 